\title{
Titanium Coagulation Simplified Removal Procedure and Alleviated Membrane Fouling in Treatment of Antimony-Containing Wastewater
}

Bingdang $\mathrm{Wu}^{\mathrm{a}}$, Jingbiao Li ${ }^{\mathrm{a}}$, Yonghai Gan ${ }^{\mathrm{a}}$, Haojie Li ${ }^{\mathrm{a}}$, Linhui Dong ${ }^{\mathrm{b}}$, Shujuan Zhang*

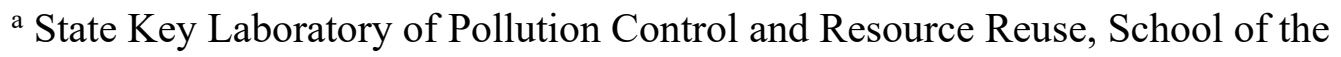

Environment, Nanjing University, 210023, PR China

b Shenzhen Changlong Technology Co., Ltd., Shenzhen 518116, PR China

Corresponding author. Tel.: +86 2589680389 .

E-mail address: sjzhang@nju.edu.cn (S.J. Zhang)

This file contains 1 Text, 1 Table and 8 Figures. 


\section{Table and Figure Captions}

Text S1. Calculation for the Resistance of Membrane.

Table S1. Water quality parameters of the effluents from a dyeing factory at Suzhou

Figure S1. Photograph (top) and schematic diagram (bottom) of the pilot test set.

Figure S2. The coagulation performance of PAC. (a) PAC with different B values, (b) PAC with PAM, (c) Photographs of the coagulation tank under different operational conditions.

Figure S3. Zeta potential of TXC.

Figure S4. (a) The COD in the biochemical effluent; (b) The residual turbidity of the coagulation effluents. TXC: $60 \mathrm{mg} / \mathrm{L}$ at $\mathrm{pH} 5.0 \pm 0.2$, PAC+PAM: from the flotation tank of the dyeing factory.

Figure S5. SEM-EDS images of the used RO membranes in the TXC and PAC+PAM systems.

Figure S6. The adsorption of $\mathrm{Sb}(\mathrm{V})$ by flocs of TXC. TXC: $60 \mathrm{mg} / \mathrm{L}, \mathrm{pH}: 7.0$.

Figure S7. The settling kinetic profiles and photos of coagulation sludge. TXC: $60 \mathrm{mg} / \mathrm{L}$, PAC: 40 mg/L, PAM: $1 \mathrm{mg} / \mathrm{L}$.

Figure S8. (a) The degradation of AO7 by the calcined TXC sludge under Xenonirradiation; (b) The adsorption of $\mathrm{Sb}(\mathrm{V})$ by the calcined TXC sludge. Calcined TXC sludge from $100 \mathrm{mg} / \mathrm{L}$ TXC: $2 \mathrm{~g} / \mathrm{L}, \mathrm{AO} 7: 70 \mathrm{mg} / \mathrm{L}, \mathrm{Sb}(\mathrm{V}): 10 \mathrm{mg} / \mathrm{L}$, initial pH: 7.0 . 


\section{Text S1. Calculation for the Resistance of Membrane}

The resistance of membrane was calculated with the resistance-in-series model, ${ }^{1}$ which is used to measure the membrane pollution degree. The specific calculation equations are as follows:

$$
\begin{aligned}
& R_{\mathrm{t}}=\frac{\mathrm{TMP}}{\mu J_{1}}=R_{\mathrm{m}}+R_{\mathrm{f}}=R_{\mathrm{m}}+R_{\mathrm{rf}}+R_{\text {irf }} \\
& R_{\mathrm{m}}=\frac{\mathrm{TMP}}{\mu J_{0}} \\
& R_{\mathrm{f}}=R_{\mathrm{t}}-R_{\mathrm{m}}=\frac{\mathrm{TMP}}{\mu J_{1}}-\frac{\mathrm{TMP}}{\mu J_{0}} \\
& R_{\text {irf }}=\frac{\mathrm{TMP}}{\mu J_{2}}-\frac{\mathrm{TMP}}{\mu J_{0}} \\
& R_{\mathrm{rf}}=R_{\mathrm{f}}-R_{\text {irf }}=\frac{\mathrm{TMP}}{\mu J_{1}}-\frac{\mathrm{TMP}}{\mu J_{2}}
\end{aligned}
$$

where $R_{\mathrm{t}}$ is the total hydraulic resistance during ultrafiltration process $\left(\mathrm{m}^{-1}\right), R_{\mathrm{m}}$ is the intrinsic membrane resistance $\left(\mathrm{m}^{-1}\right), R_{\mathrm{f}}$ is the fouling resistance caused by pollutants during filtration $\left(\mathrm{m}^{-1}\right) . R_{\mathrm{f}}$ includes hydraulic reversible resistance $\left(R_{\mathrm{rf}}\right)$ and irreversible resistance $\left(R_{\text {irf }}\right)$. TMP is the trans-membrane pressure $(\mathrm{Pa}), \mu$ is the dynamic viscosity of the feedwater $(\mathrm{Pa} \cdot \mathrm{s}), J_{0}, J_{1}$, and $J_{2}$ are the permeate fluxes $\left(\mathrm{m}^{3} \cdot \mathrm{m}^{-2} \cdot \mathrm{s}^{-1}\right)$ of a clean membrane, the fouled membrane, and the membrane after backwash, respectively.

\section{Reference}

(1) Lin, C. F.; Lin, Y. C.; Chandana, P.; Tsai, C.Y. Effects of mass retention of dissolved organic matter and membrane pore size on membrane fouling and flux decline. Water Res. 2009, 43 (2), 389-394. 
Table S1. Water quality parameters of the effluents from a dyeing factory at Suzhou

\begin{tabular}{lccc}
\hline Item & $\begin{array}{c}\text { Biochemical } \\
\text { effluent }\end{array}$ & $\begin{array}{c}\text { PAC+PAM flotation } \\
\text { effluent }\end{array}$ & RO concentrate \\
\hline $\mathrm{pH}$ & $6.5-7.5$ & 5.0 & $6.5-7.5$ \\
Turbidity (NTU) & $52-152$ & $0.9-3.5$ & $0.9-3.5$ \\
$\mathrm{Sb}(\mu \mathrm{g} / \mathrm{L})$ & $226-894$ & $207-800$ & $774-2370$ \\
$\mathrm{COD}(\mathrm{mg} / \mathrm{L})$ & $236-682$ & $143-594$ & $400-600$ \\
Conductivity $(\mathrm{mS} / \mathrm{cm})$ & $2.4-3.5$ & $3.0-3.7$ & $4.6-5.3$ \\
& & & \\
\hline
\end{tabular}



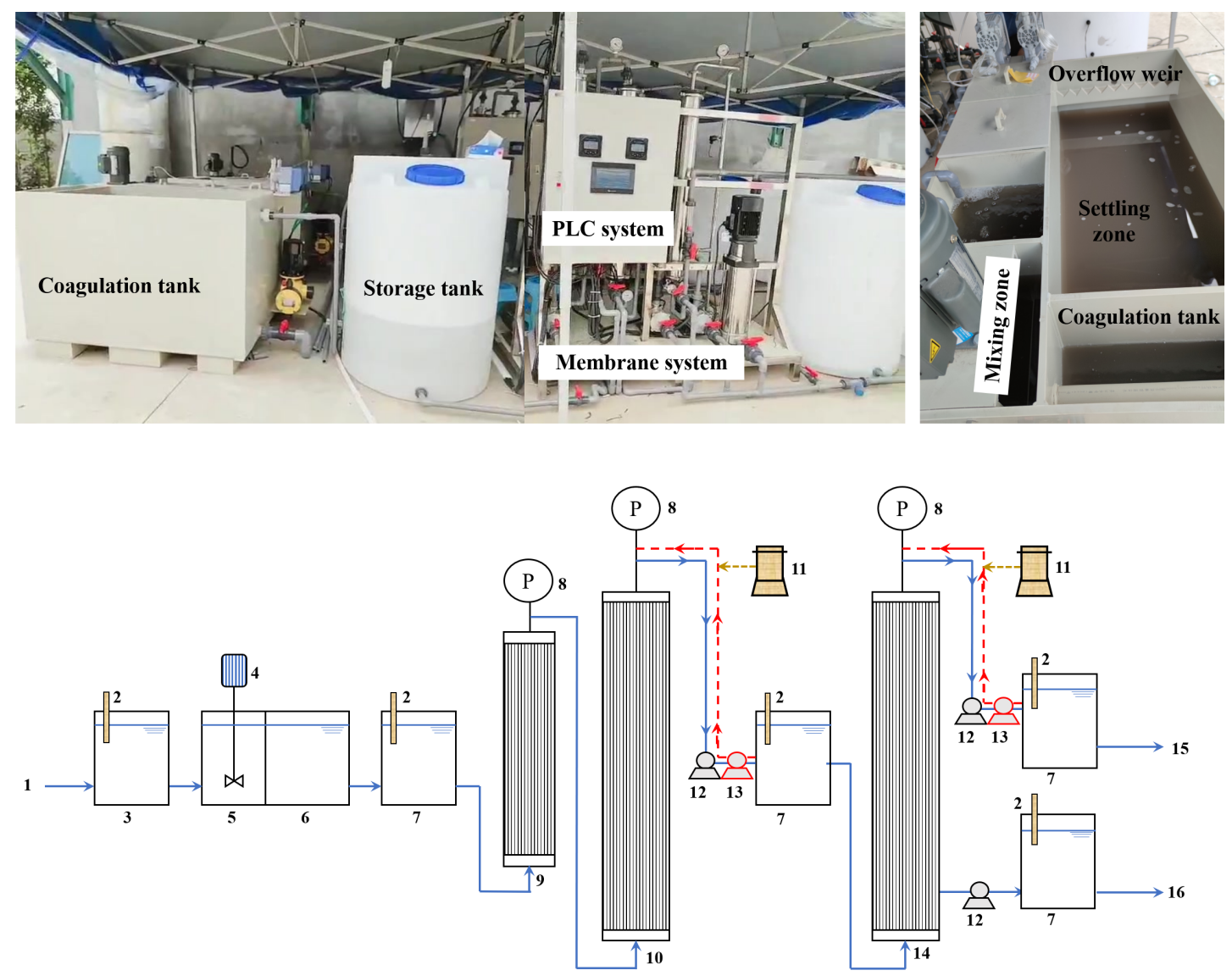

1. raw water; 2. pH meter; 3. raw water tank; 4. mechanical stirrer; 5. mixing tank; 6. settling tank; 7. storage tank; 8. pressure gauge; 9. security filter; 10 . UF membrane system; 11 . cleaning system; 12 . suction peristaltic pump; 13 . back wash peristaltic pump; 14. RO membrane system; 15 . produced water; 16 . RO concentrate.

Figure S1. Photograph (top) and schematic diagram (bottom) of the pilot test set. 

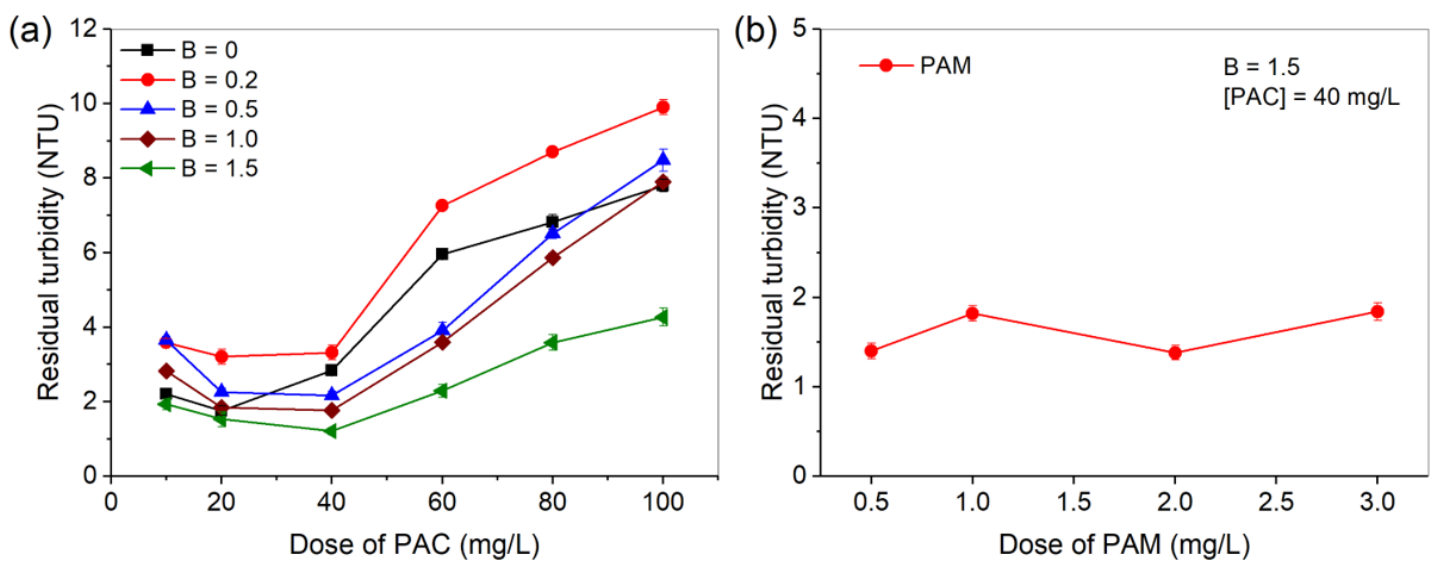

(c)
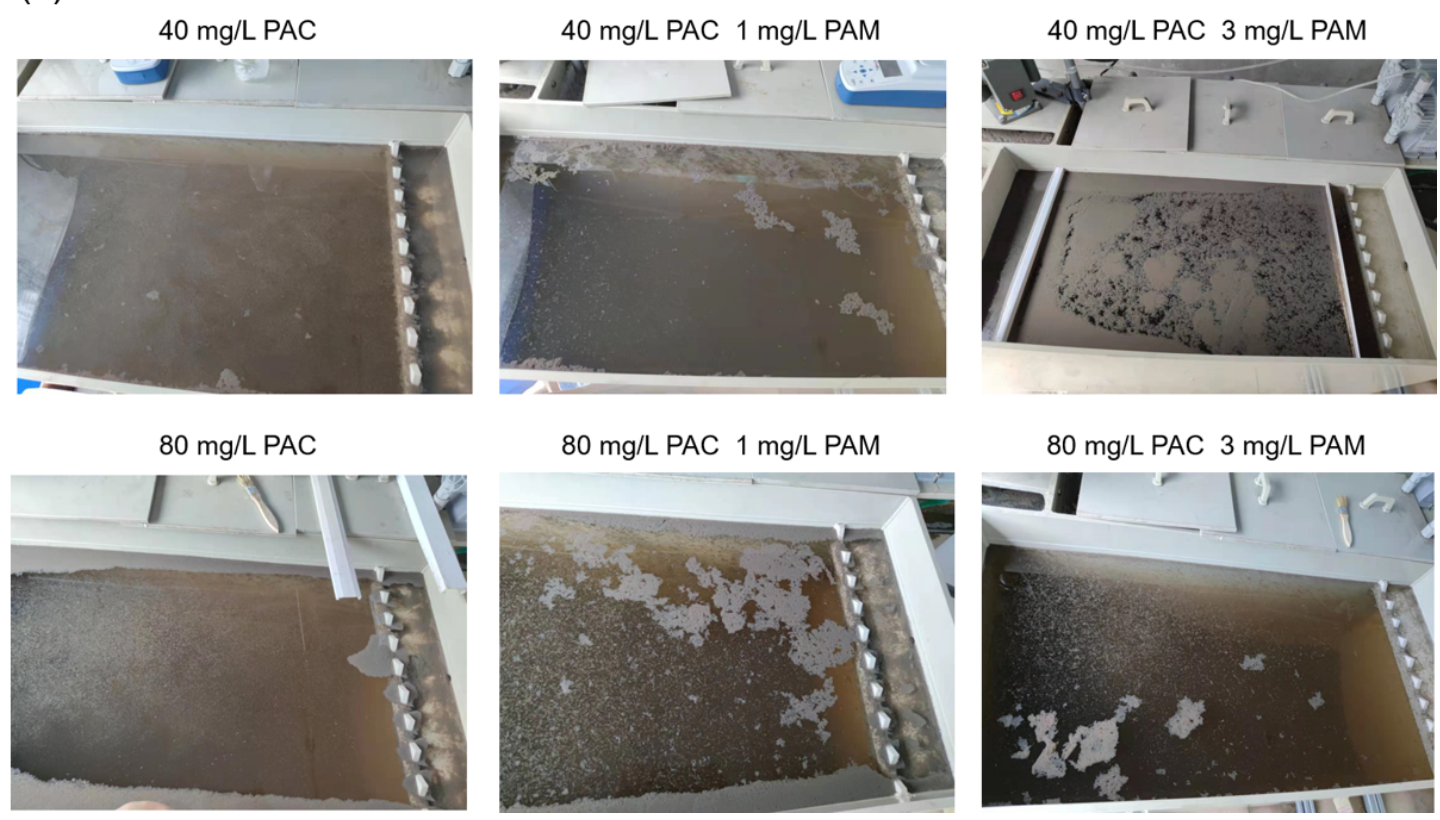

Figure S2. The coagulation performance of PAC. (a) PAC with different B values; (b) PAC with PAM; (c) Photographs of the coagulation tank under different operational conditions. 


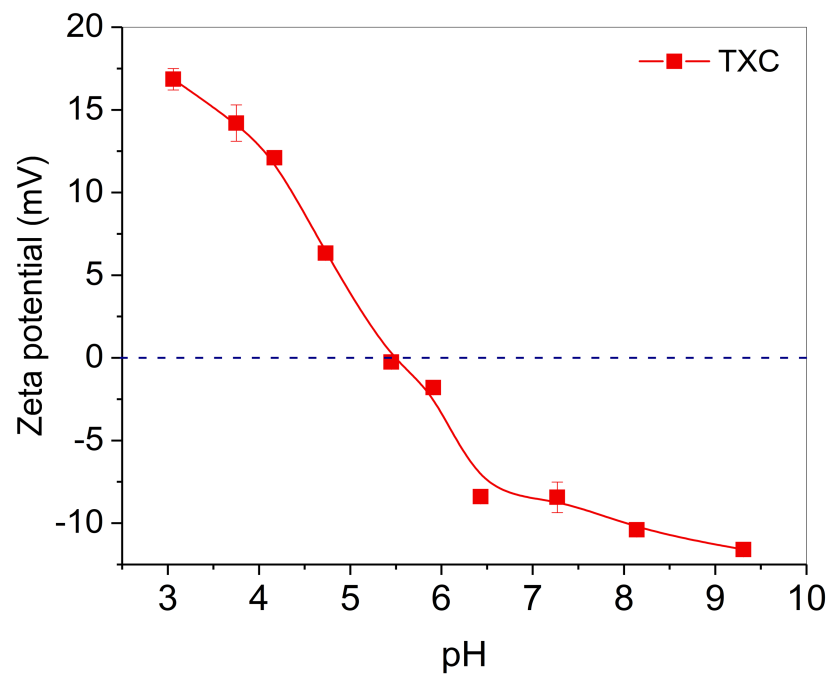

Figure S3. Zeta potential of TXC in aqueous solutions.
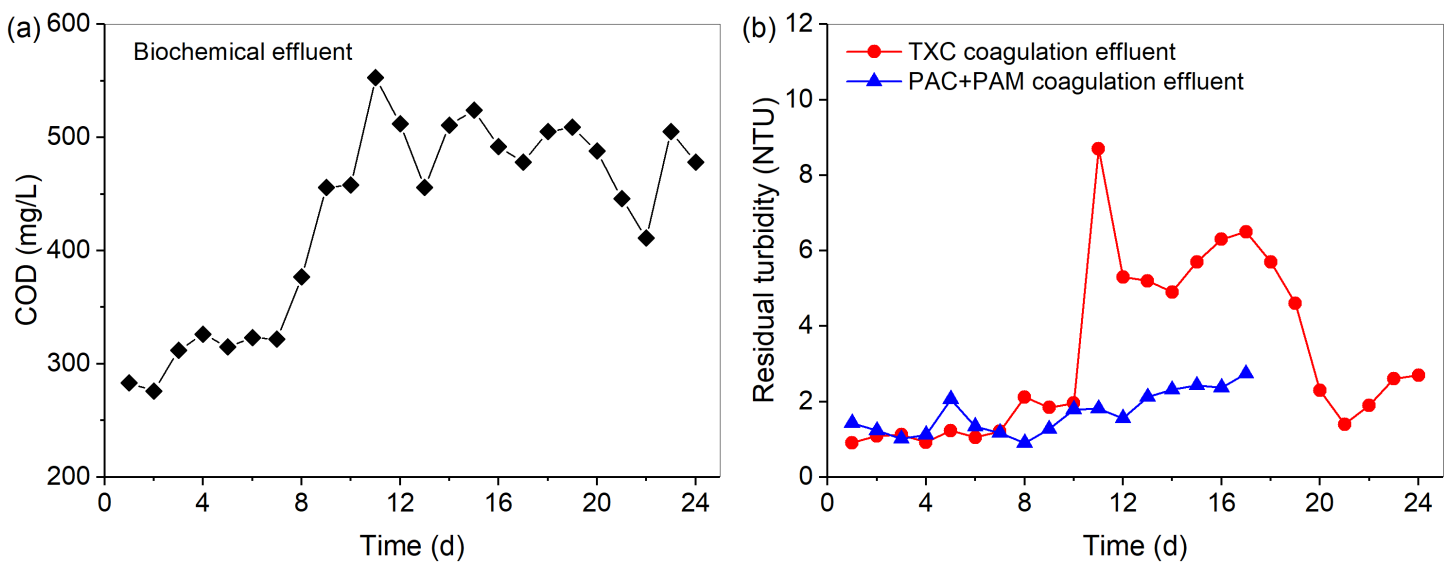

Figure S4. (a) The COD in the biochemical effluent; (b) The residual turbidity of the coagulation effluents. TXC: $60 \mathrm{mg} / \mathrm{L}$ at $\mathrm{pH} 5.0 \pm 0.2$, PAC+PAM: from the flotation tank of the dyeing factory. 

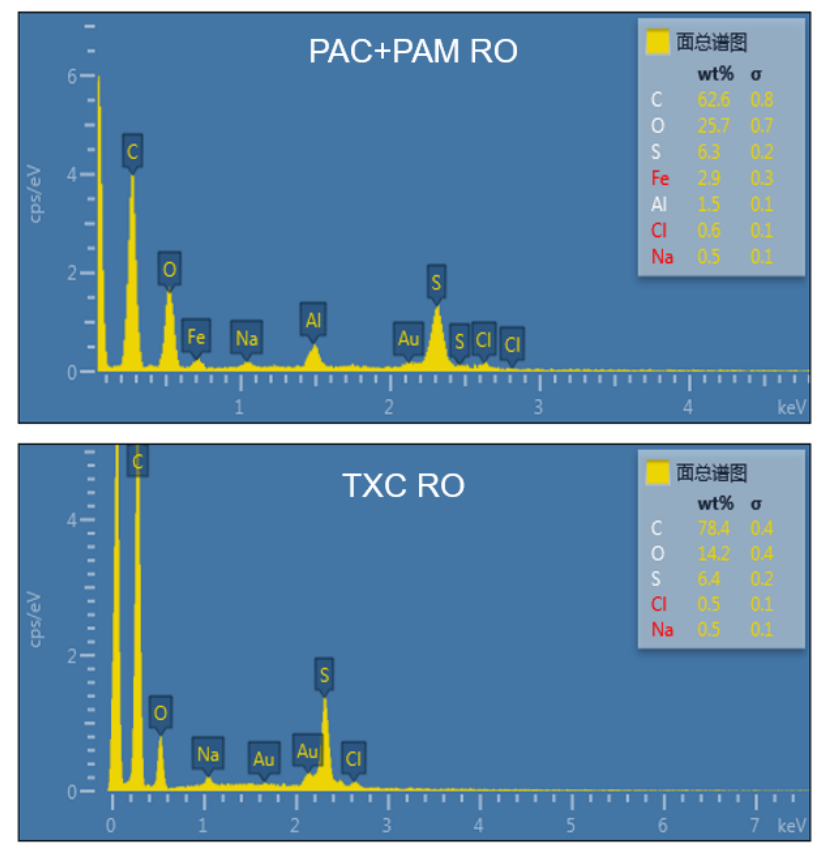

Figure S5. SEM-EDS images of the used RO membranes in the TXC and PAC+PAM systems.

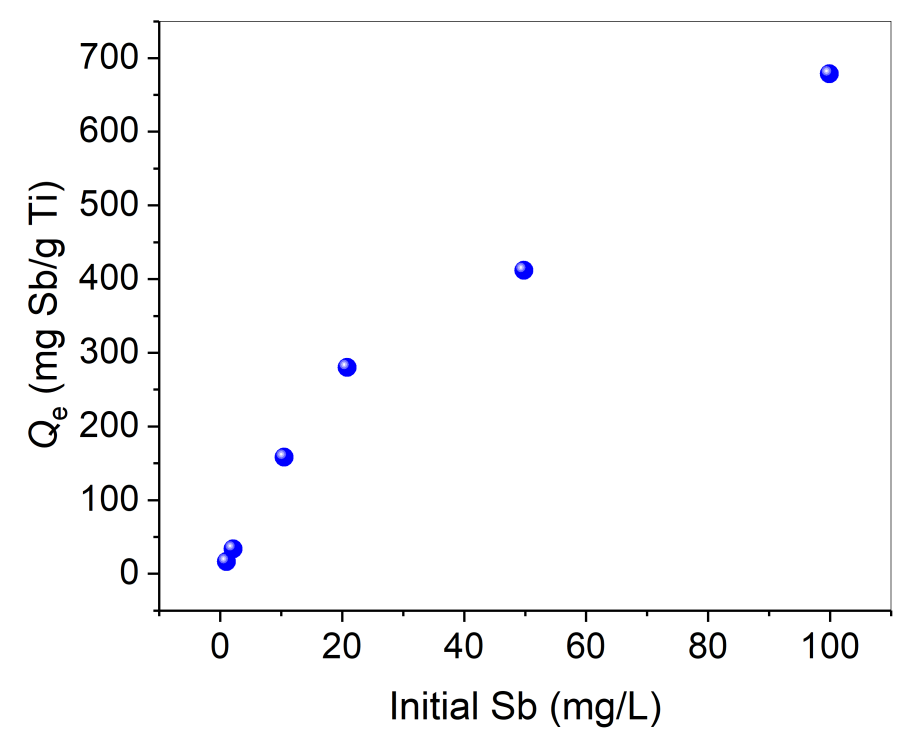

Figure S6. The adsorption of $\mathrm{Sb}(\mathrm{V})$ by flocs of TXC. TXC: $60 \mathrm{mg} / \mathrm{L}, \mathrm{pH}: 7.0$. 

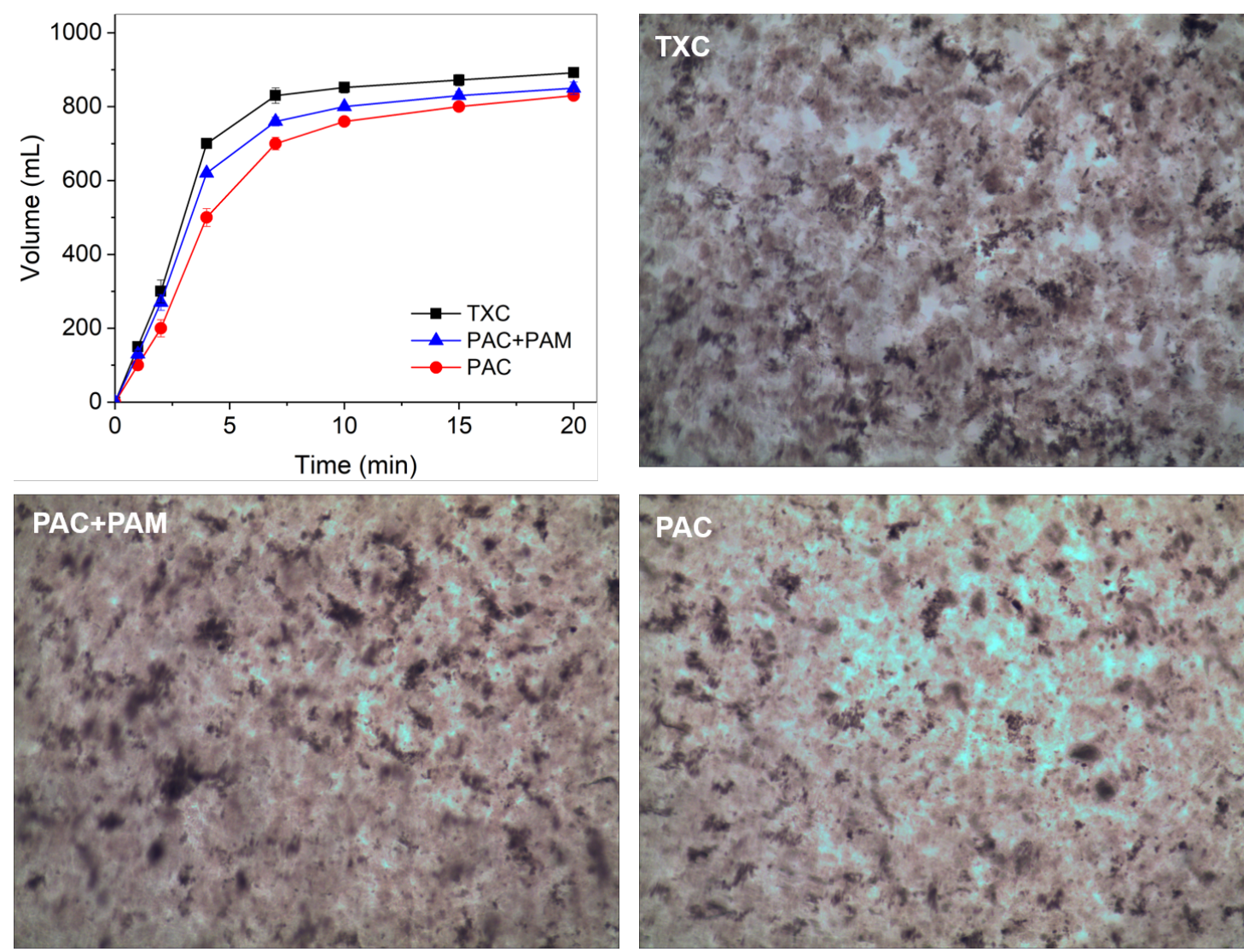

Figure S7. The settling kinetic profiles and photos of coagulation sludge. TXC: $60 \mathrm{mg} / \mathrm{L}$, PAC: $40 \mathrm{mg} / \mathrm{L}$, PAM: $1 \mathrm{mg} / \mathrm{L}$. 

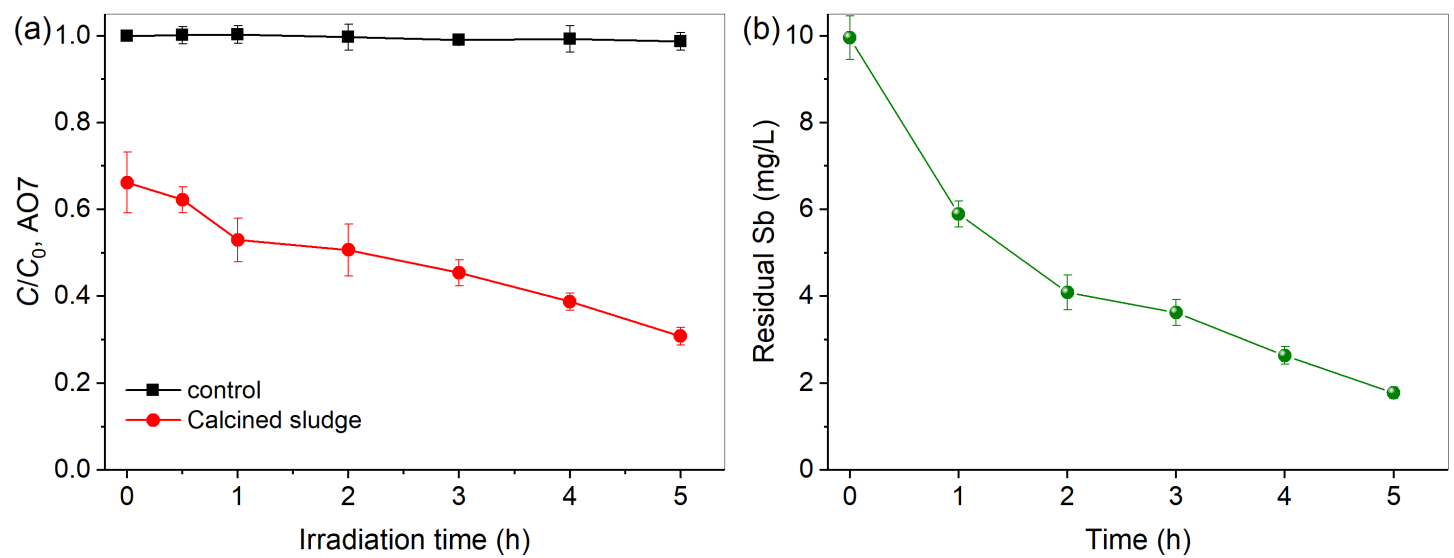

Figure S8. (a) The degradation of AO7 by the calcined TXC sludge under Xenonirradiation; (b) The adsorption of $\mathrm{Sb}(\mathrm{V})$ by the calcined TXC sludge. Calcined TXC sludge from $100 \mathrm{mg} / \mathrm{L}$ TXC: 2 g/L, AO7: $70 \mathrm{mg} / \mathrm{L}, \mathrm{Sb}(\mathrm{V}): 10 \mathrm{mg} / \mathrm{L}$, initial pH: 7.0 . 